\title{
Pseudempleurosoma gibsoni n. sp., a New Ancyrocephalid Monogenean from Paralonchurus brasiliensis (Sciaenidae) from off the Southeastern Coast of Brazil
}

\author{
Cláudia P Santos ${ }^{+}$, Elizabeth D Mourão, Melissa Q Cárdenas \\ Instituto de Ciências Biológicas e Ambientais, Universidade Santa Úrsula, Rua Fernando Ferrari 75, \\ 22231-040 Rio de Janeiro, RJ, Brasil
}

Pseudempleurosoma gibsoni $n$. sp. (Monogenea: Ancyrocephalidae) is described from the oesophagus of Paralonchurus brasiliensis (Steindachner) from off the coast of Brazil. The type-species of Pseudempleurosoma Yamaguti, 1965, P. carangis Yamaguti, 1965, is redescribed and the diagnosis of the genus is amended. Metadiplectanotrema Gerasev et al. 1987 is considered synonym of Pseudempleurosoma. This genus now contains four species, including P. carangis, P. caranxi Gerasev et al., 1987 n. comb., P. myripristi Gerasev et al., 1987 n. comb. and the one new species.

Key words: Pseudempleurosoma gibsoni n. sp.- Monogenea - Ancyrocephalidae - Paralonchurus brasiliensis fish - Brazil

During 1999 several specimens of an ancyrocephalid monogenean were collected from the oesophagus of the sciaenid fish Paralonchurus brasiliensis (Steindachner) captured off the northern coast of the state of São Paulo, Brazil. The site of the parasite is somewhat unusual, as monogeneans are generally considered as ectoparasites. Few monogeneans are known to be adapted to an endoparasitic existence. For example, in the foregut Diplectanotrema Johnston and Tiegs, 1922, Pseudempleurosoma Yamaguti, 1965, Neodiplectanotrema Gerasev et al., 1987, Paradiplectanotrema Gerasev et al., 1987, Pseudodiplectanotrema Gerasev et al.,1987 and Metadiplectanotrema Gerasev et al., 1987 are known to parasitise the pharynx and oesophagus of marine fishes, while Enterogyrus Paperna, 1963 is recorded as inhabiting the stomach of freshwater fishes. The monogenean described herein represents a new species of the genus Pseudempleurosoma Yamaguti,1965.

\section{MATERIALS AND METHODS}

During an oceanographic cruise along the coast of Ubatuba, State of São Paulo, Brazil, an otter trawl was used at $20 \mathrm{~m}$ deep to catch fish hosts

\footnotetext{
Financial support by CNPq, Conselho Nacional de Pesquisa.

${ }^{+}$Corresponding author. Fax: +55-21-551.6446. E-mail: cpsantos@ax.apc.org

Received 26 April 2000

Accepted 20 September 2000
}

between $23^{\circ} \mathrm{S}, 045^{\circ} \mathrm{W}$ and $23^{\circ} 35^{\prime} \mathrm{S}, 045^{\circ} 06^{\prime} \mathrm{W}$. Fish were frozen immediately after capture and examined later for parasites. The worms recovered were fixed and stored in 70\% alcohol, stained in Mayer's paracarmine, dehydrated in an ethanol series, cleared in creosote and mounted in Canada balsam, or were directly mounted in Hoyer's medium and studied with phase-contrast and differential interference microscopy. Measurements are in micrometres. Hamuli were measured only as straight line measurements from the tip of the ventral root to the apex of the curve of the blade. Illustrations were made with the aid of a drawing apparatus.

Ecological terms used follow Busch et al. (1997). During the study the holotype and paratypes of Pseudempleurosoma carangis Yamaguti, 1965 from the US National Parasite Collection (no. 971-6) were examined. Type-specimens of the new species are deposited in the Helminthological Collection of Oswaldo Cruz Institute (CHIOC).

\section{RESULTS}

Family Ancyrocephalidae Bychowsky \& Nagibina, 1978

Pseudempleurosoma Yamaguti, 1965

Syn. Metadiplectanotrema Gerasev et al., 1987 (new synonymy)

Pseudempleurosoma gibsoni $\mathrm{n}$. sp.

Type-host: Paralonchurus brasiliensis (Steindachner) ( Sciaenidae)

Type-locality: off Ubatuba, State of São Paulo, Brazil $\left(23^{\circ} \mathrm{S}, 045^{\circ} \mathrm{W}-23^{\circ} 35^{\prime} \mathrm{S}, 045^{\circ} 06^{\prime} \mathrm{W}\right)$ 
Habitat: oesophagous

Type-material: holotype CHIOC 34.337-a; paratypes CHIOC $34.337 \mathrm{~b}$-e and 34.338

Infection: sixteen of 41 fish examined harboured 70 specimens. Prevalence $39 \%$, mean intensity 4.3 and mean abundance 1.7

Description (Figs 1-5): based on 18 specimens. Body slender, unspined, 950-1,540 (1,228) long; maximum width 161-308 (222) wide. Single pair of head glands extend to pharyngeal region (Fig. 5). Two pairs of eye-spots. Oral aperture ventral, 23-43 (32) from anterior end; pharynx globular, $51-78 \times 51-78(60 \times 66)$. Intestinal caeca united posterior to testis, with lateral diverticula lacking haematin pigment. Haptor, 55-92 x 80-92 (83 x 84 ), not distinctly set off from body; 2 pairs of dissimilar hamuli and 14 marginal hooks. Dorsal hamuli 41-58 (46) in length are connected by a single quadrangular dorsal bar, 12-16 x 14-18 (14 $x$ 16) (Fig. 2). Ventral hamuli 12-14 (12) in length, each one with two bars: one attached of 12-16 (14) in length and a free irregular bar of 14-23 (17) in length (Fig. 3a-b). Marginal hooks 14-18 (15) long (Fig. 3c). Genital atrium median, smooth, at 108-172 (140) from anterior end. Copulatory organ sclerotized, tubular, 43-62 (51) long, with seminal vesicle and prostatic reservoir at base; accessory piece partly sclerotized, irregular in shape, 2132 (25) long (Figs 1, 5). Testis post-ovarian, oval, $36-65$ x 27-51 (47 x 33); vas deferens encircles the left intestinal branch. Ovary turned back on itself, giving an appearance of being round, 46-92 x $46-82$ (68 x 70). Vagina simple opens at level of genital atrium. Vitelline follicles arranged longitudinally in lateral fields along body. Vitelline ducts unite anteriorly to ovary, at 109-135 (120) from anterior end. Uterus sacciform, ends as muscular aperture of $18-30 \times 23-27(24 \times 24)$, in genital atrium (Fig. 5). Eggs 78-110 x 58-97 (92x78), with single short, coiled polar filament, 7-9 (8) long (Fig. 4).

Etymology: the specific name is for Dr David Gibson, The Natural History Museum, for his helpful contributions to parasitology.

Pseudempleurosoma carangis Yamaguti, 1965

Type-host: Caranx lugubris Poey, 1860 (Carangidae)

Type-locality: Hawaii

Habitat: pharynx and gills

Type-material: holotype and paratypes USNPC no. 971-6

Redescription (Figs 6-9): based on 10 specimens. Body slender, unspined, 847-1,112 (974) long; maximum width 169-261 (217). Single pair of head glands extend to pharyngeal region. Two pairs of eye-spots. Pharynx 46-60 x 55-78 (53 x 66). Intestinal caeca unite posterior to testis, with numerous lateral diverticula lacking haematin pigment. Haptor 46-92 x 73-100 (64 x 82), with 2 pairs of dissimilar hamuli and 14 marginal hooks. Dorsal hamuli 46-50 (49) in length, with long deeply-concave root; single, quadrangular dorsal bar, $14-16 \mathrm{x}$ 14-16 (15 x 15) (Fig. 6). Ventral hamuli 9-12 (11) in length, each with two ventral bars: attached ventral bar 12-14 (12.4) long, free irregular bar 12-14 (12.4) long (Fig. 7a-b). Marginal hooks 14-16 (14.4) long (Fig. 7c). Genital atrium median. Gonads intercaecal, tandem; testis post-ovarian, 41$55 \times 32-50(50 \times 44)$. Sclerotized copulatory organ tubular, 39-50 (41) long, twisted in middle at level of accessory piece, with proximal muscular sheath with small terminal spiniform projections. Seminal vesicle and prostatic reservoir at base (Fig. 8). Ovary turned back on itself, 55-97 x 55-69 (74 $x$ 63) long. Oötype gives rise to uterus and nonsclerotized vagina. Vaginal opening close to genital atrium, at level of the muscular opening of uterus which measures 21-27 x 23-25 (25x24). Vitelline follicles in longitudinal, lateral fields along body. Vitelline ducts unite just anterior to ovary. Eggs 60-105 x 48-73 (65 x 55), without filament (Fig. $9)$.

\section{DISCUSSION}

Of all parasites, monogeneans are generally the most specific, selecting and adapting to specific sites, hosts and macro-environments (marine, brackish or freshwater). Among those which inhabit the foregut of fishes, Enterogyrus from the stomach of freshwater fishes and the marine 'diplectanotrema-group' (Diplectanotrema, Pseudempleurosoma, Neodiplectanotrema, Paradiplectanotrema, Pseudodiplectanotrema and Metadiplectanotrema) present different levels of adaptation. Enterogyrus spp. can be readily differentiated from the others by their thick tegument, rudimentary head organs, caeca without diverticula and distribution of vitelline follicles, while the endoparasitc ancyrocephalids all have a thin tegument, a single pair of conspicuous, long head organs and a vitellarium typically arranged in a linear series throughout the length of the body.

Among the 'diplectanotrema-group', Diplectanotrema has an accessory piece associated with the copulatory organ but lacks ventral bars. Neodiplectanotrema is characterised by a copulatory organ with two glandular reservoirs but no associated accessory piece, one connecting ventral bar linked to each ventral hamulus and the absence of a sucker at the end of the oötype. After Gerasev et al., in Paradiplectanotrema there is one 

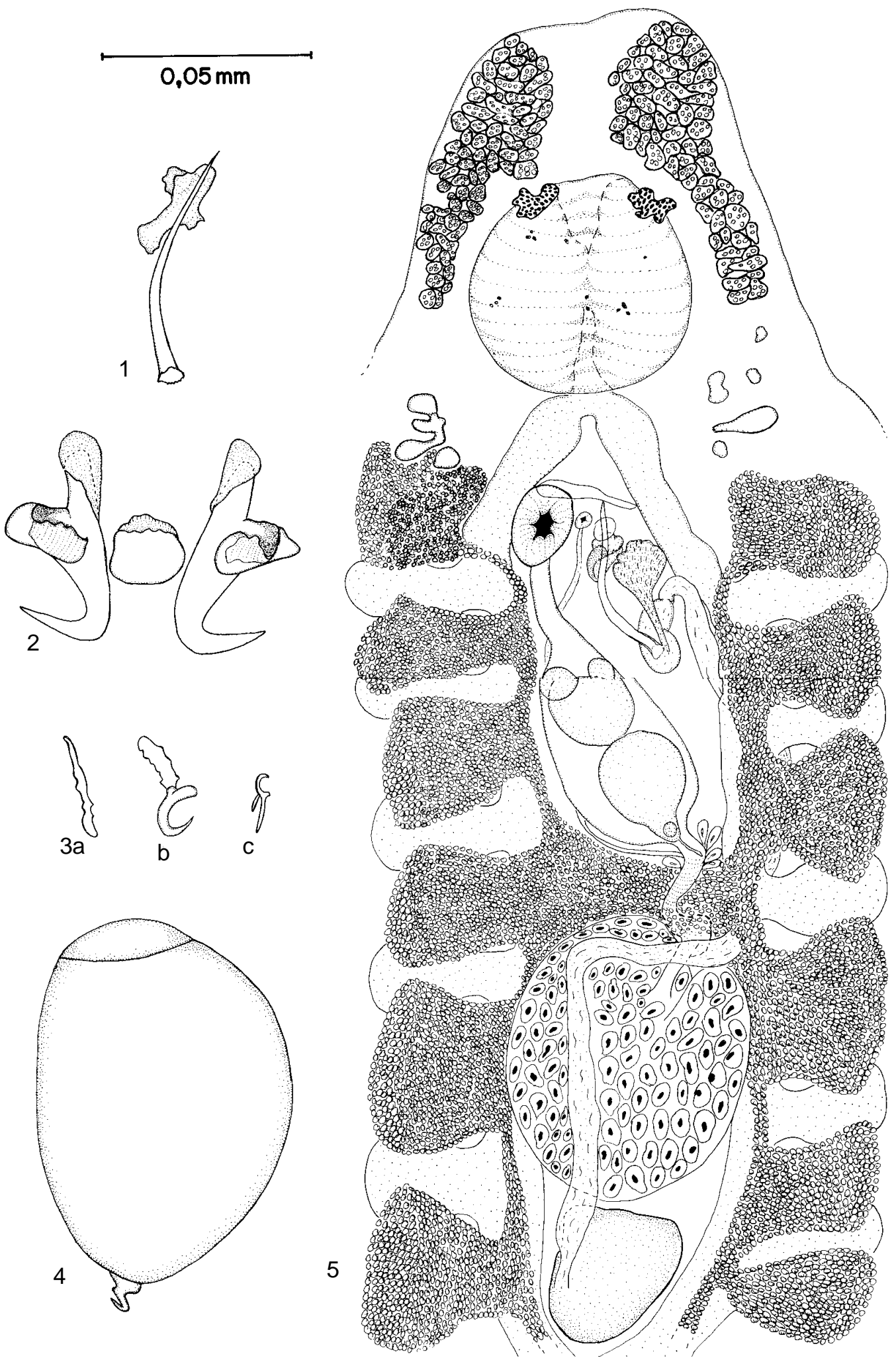

Pseudempleurosoma gibsoni $\mathrm{n}$. sp. Fig. 1: copulatory organ and acessory piece. Fig. 2: dorsal hamuli with single dorsal bar. Fig. 3a: free irregular ventral bar; b: ventral hamulus with attached bar; c: marginal hook. Fig. 4: egg. Fig. 5: anterior end with detail of reproductive system 

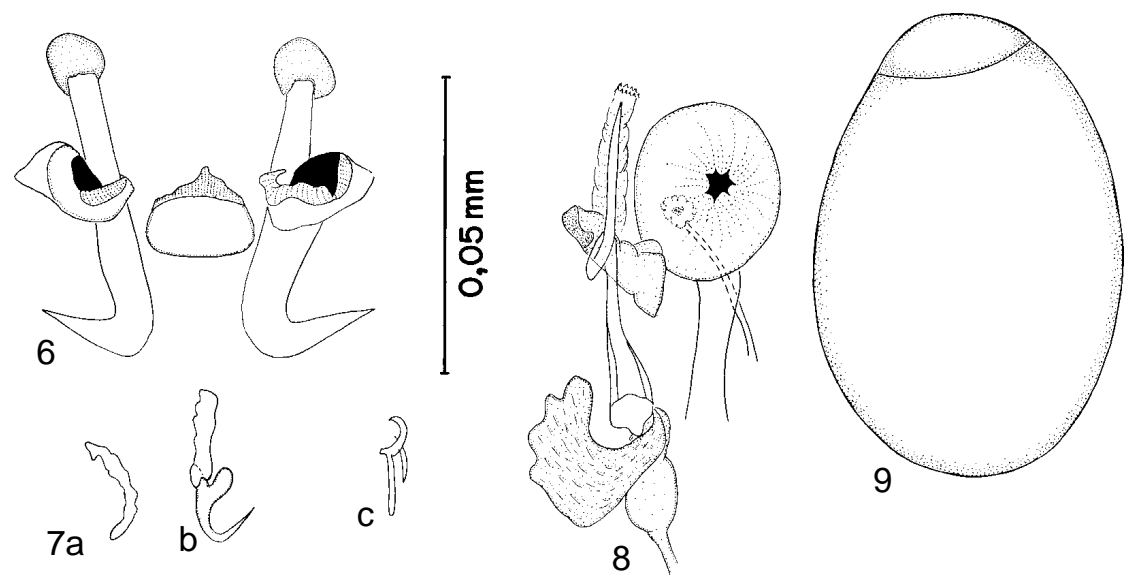

Psedempleurosoma carangis Yamaguti, 1965. Fig. 6: dorsal hamuli with single dorsal bar bar. Fig. 7a: free ventral bar; b: ventral hamulus with attached ventral bar; c: maginal hook. Fig. 8: reproductive system. Fig. 9: egg.

connecting ventral bar with each ventral hamulus, a large sucker at the end of the oötype, a "compound seminal receptacle" (one seminal vesicle and two prostatic reservoirs together) and a copulatory organ with an accessory piece. Pseudodiplectanotrema, although exhibiting a sucker at the end of the oötype, has neither an accessory piece associated with the copulatory organ nor a ventral connecting bar.

Pseudempleurosoma with only one species, $P$. carangis Yamaguti, 1965 from Caranx lugubris, C. sexfasciatus and Myripristis berndti off Hawaii, is close to Metadiplectanotrema, which has two species, M. caranxi Gerasev et al., 1987 and $M$. myripristi Gerasev et al.,1987, collected from $C$. ruber and M. jacobus, respectively, in the Caribbean Sea. Metadiplectanotrema was said to differ from Pseudempleurosoma by the presence of two rather than one ventral bars associated with each ventral hamulus and by the presence of an accessory piece in the copulatory organ. A re-examination of the holotype and paratypes of $P$. carangis has revealed that there are in fact two linked bars to each ventral hamulus, one attached and the other detached; this was probably interpreted by Yamaguti (1968) as "anterior medial hooklets abnormally large". The accessory piece, although difficult to see in the types, is also present. Consequently, Metadiplectanotrema is here considered a junior synonym of Pseudempleurosoma. Vagina that was originally described as absent is now described as a thin, non sclerotized chanel, opening close to muscular disc of uterus in a similar pattern described for Enterogyrus species (Gussev \& Fernando 1973).
$M$. caranxi, which becomes $P$. caranxi n. comb., needs to be re-examined (the types are not available, P Gerasev, pers. commun.) because it is recorded from the same genus of host as host group to $P$. carangis, but it appears to have larger dorsal and ventral bars. M. myripristi, which becomes $P$. myripristi n. comb., notwithstanding the similarities in size and host, is considered a valid species because of the presence of a long polar filament on the eggs and a larger dorsal bar.

Unnamed Pseudempleurosoma spp. have also been reported in Chlorophthalmus punctatus and Hoploichthys acanthopleurus from the SW Indian Ocean off the coast of East Africa (Reimer 1990), in Sillago ingenииа from the coast of Indonesia and Malaysia (Hayward 1997, Lim 1998). Hayward (1997), based in one specimen, pointed out that there were three dorsal bars instead of one. In $P$. carangis and $P$. gibsoni n. sp., the roots of each dorsal hamulus are concave, giving the appearance of bars, but in reality there is only one dorsal bar between hamulus.

$P$. gibsoni n. sp. differs from $P$. carangis in the shape of the cirrus, the absence of spiniform structures around muscular sheath of cirrus and by the presence of a filament on the eggs, in addition to host and geographical distribution. From P. caranxi it differs mainly in the presence of a filament on the eggs, the size and rectangular shape of the dorsal bar, the size of the attached ventral bar, the host and geographical distribution. From M. myripristi, it can be differentiated by the smaller sizes of the dorsal bar and the filament on the eggs, the larger size of the marginal hooks, host and geographical distribution (Table). 


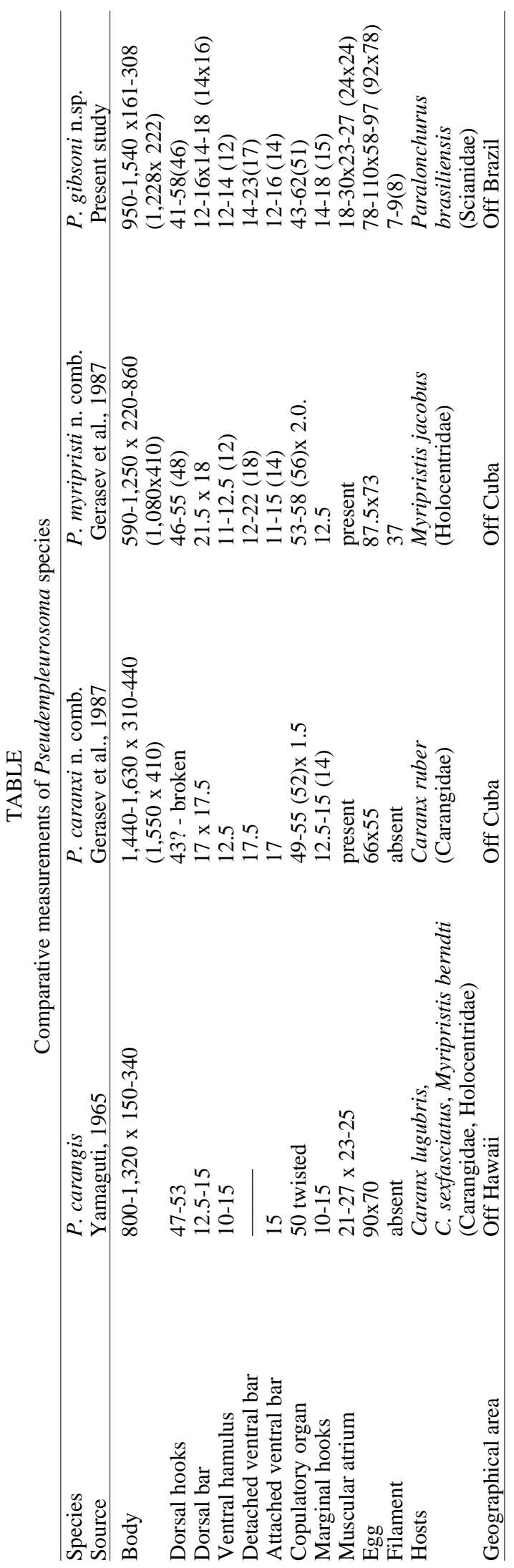

Pseudempleurosoma Yamaguti, 1965

\section{Amended diagnosis}

Ancyrocephalidae: body more or less uniform in width. Haptor truncate, shallowly constricted from body proper, armed with 14 marginal hooks, 2 pairs of dissimilar hamuli: dorsal hamuli larger, with unpaired median connecting bar; ventral hamuli smaller, with two pairs of connecting bars associated with each hamulus. Two pairs of eye-spots present. Oesophagus short; caeca with numerous lateral diverticula, united posteriorly. Testis in about middle of anterior half of body; seminal vesicle and prostatic reservoir near base of copulatory apparatus. Copulatory organ tubular, slender, twisted or not; accessory piece present. Genital pore median. Ovary immediately pretesticular. Uterus opens in a small, muscular disc that projects into genital atrium close to vagina. Eggs with or without polar filament, produced singly. Vitellarium divided into numerous, transversely elongate follicles; lateral fields co-extensive with caeca and their diverticula; transverse vitelline duct immediately pre-ovarian. Pharynx and oesophagus, rarely gills of marine teleosts. Type species P. carangis Yamaguti, 1965.

\section{ACKNOWLEDGEMENTS}

To Dr Pavel I Gerasev, Department of Parasitic Worms, Zoological Institute, Russian Academy of Science, for information concerning specimens; Dr Eric Hoberg from US National Parasite Collection, for the loan of types; Dr David I Gibson, The Natural History Museum, London, for providing literature; Dr Josefina Kurtz , Universidade Santa Úrsula for fish samples and Dr Walter Boeger for comments.

\section{REFERENCES}

Bush AO, Lafferty KD, Lotz JM, Shostak AW 1997. Parasitology meets ecology on its own terms: Margolis et al. revisited. J Parasitol 83: 575-583.

Gussev AV, Fernando CH 1973. Dactylogyridae (Monogenoidea) from the stomach of fishes. Folia Parasitol 20: 207-212.

Hayward CJ 1997. Helminth ectoparasites of sillaginid fishes (Perciformes: Percoidei) have low species richness. Folia Parasitol 44: 173-187.

Lim LHS 1998. Diversity of monogeneans in Southeast Asia. Int J Parasitol 28: 1495-1515.

Reimer L 1990. Monogenea von Fischen der Kusten von Namibia und Mocambique. Wissenschaftliche Zeitschrift der Padagogischen Hochschule 'Liselotte Herrman' Güstrow : 27-38.

Yamaguti S 1968. Monogenetic Trematodes of Hawaiian Fishes, University of Hawaii Press, Honolulu, $287 \mathrm{pp}$. 